TITLE:

\title{
ALEOCHARINAE (STAPHYLINIDAE, COLEOPTERA) FROM THE CAMPUS OF THE SETO MARINE BIOLOGICAL LABORATORY
}

$\operatorname{AUTHOR}(\mathrm{S})$ :

Sawada, Kohei

CITATION:

Sawada, Kohei. ALEOCHARINAE (STAPHYLINIDAE, COLEOPTERA) FROM THE CAMPUS OF THE SETO MARINE BIOLOGICAL LABORATORY. PUBLICATIONS OF THE SETO MARINE BIOLOGICAL LABORATORY 1971, 18(5): 291-315

ISSUE DATE:

1971-01-30

URL:

http://hdl.handle.net/2433/175644

RIGHT: 


\title{
ALEOCHARINAE (STAPHYLINIDAE, COLEOPTERA) FROM THE CAMPUS OF THE SETO MARINE BIOLOGICAL LABORATORY ${ }^{1}$
}

\author{
KOHEI SAWADA \\ 15-10 Tennocho, Takatsuki, Osaka, Japan
}

With 9 Text-figures

Next to the Aleocharinae research in the Shiga Heights, central Japan, my attention has been arrested by the Aleocharinae fauna of the sea-shore and the forest directly facing the sea. The Seto Marine Biological Laboratory furnishes the ideal area for this purpose and the repeated visits in 1969-1970 have afforded me a rich material of Aleocharinae within the campus to be investigated.

In résumé the habitat of Aleocharinae in and around the laboratory may be divided into three zones: the first zone is the floor of the temperate mixed forest composed mainly of Pinus thunbergii covering the hills and dunes of the neighbourhood. In the humus layer of the forest two species of Aleocharinae are collected. The dominant member of them is Tomoglossa cuspidata sp. $\mathrm{n}$. and the other is Brachida brevipennis Bernhauer which is found mingled with the former. They are inhabitants of the forest and never emerge from other habitat of the area.

Secondly, the wrack along the sea-shore furnishes the nice source to nourish the Aleocharinae. By only shaking the heap of algae stranded on the sandy beach on a white sheet, many Staphylinidae and other insects will be scattered on the sheet together with an amphipod, Orchestia, and other littoral animals. Aleocharinae species inhabiting such a wrack are special forms which are concentrated to limitedly the algal heap of the sea-shore, but are never found in other habitats. They must be regarded as the halophilous species confined to the wrack. From Seto seven species of the wrack Aleocharinae have been found. They are included in 3 main genera, Ischnopoda, Myrmecopora and Aleochara (Emplenota). Some animal detritus and carcasses left on the shore are also the source of Aleocharinae, but the species gathered on them are not halophilous, but common inland saprophagous species. In Seto they are represented by Ischnopoda (Coproceramius) atramentaria GyllenhaL.

Lastly there may be found some halophilous Aleocharinae that live in the intertidal zone of the reef and the rocky shore such as Liparocephalus tokunagai SAKAGUTI, Halesthenus sp. and Genoplectes sp. which are already found in the vicinity of Seto.

1) Contributions from the Seto Marine Biological Laboratory, No. 534.

Publ. Seto Mar. Biol. Lab., XVIII (5), 291-315, 1971. (Article 22) 
They may be regarded as true halobionts with the ability to survive the submersion under the sea-water for a long time.

In the present paper the Aleocharinae species which live on the forest floor or among the algal wracks of the shore in the campus of the Laboratory are treated. Studies of the halobionts of the third category around the whole Kii peninsula are now going on, to be published later.

Before going further I wish to express my hearty thanks to Prof. T. TokiokA and to the staff of the Seto Marine Biological Laboratory for their constant help and also to Prof. R. Yosin for the critical review of the manuscript.

\section{Brachida brevipennis BERNHAUER, 1938}

(Fig. 1)

ㅇ․ Rufotestaceous and shining. Head and pronotum are more or less infuscate; the distal half of abdomen is nearly black; antennae are paler distally; legs are uniformly pigmented. Head is gently convex above, nearly straight laterally and without depression; there are 2 pairs of erecting setae on the epicranium; punctures are fine and denser toward the post-ocular region, excepting the subglabrous area between antennae; microsculpture is represented by fine, but dense reticulation. Eye is about as long as the post-ocular region and with curved setae fairly longer than the diameter of a cornea. Antenna is dilated distally, compressed on the first segment and with long conspicuous setae on the flagellum; ratio of segments as: I $15 \times 11:$ II $12 \times 7:$ III $8 \times 6:$ IV $7.5 \times 7: \mathrm{X} 7 \times 13: \mathrm{XI} 17 \times 12$. Labrum is distinctly emarginate and broadly rounded along the corner; seta $p-1, p-2$ are subequally long and markedly pigmented; $m-1$ is subequal to the secondary seta in length; the proximal row is longer than others; the medial row is oblique laterally which is the very marked character of the genus. Marginal sensillae of labrum are aggregated medially; $a$-sensilla is reduced to short, blunt spine; $b$ is so long as $a$ and submerged into the deep median incision of the margin; $c$ is protruded. Mandible is briefly pointed and forked apically; the right one has a distinct median tooth. Segment I of maxillary palpus bears a spinula exteriorly; II is fairly dilated in the middle and narrowed distally, with a sinuate inner margin and without microsculpture; the first seta of the outer margin is converted to a setula; III is a little longer and more dilated than the preceding and with numerous long setae; IV is long, subulate and without apical spinula; basal filamentous sensillae are quite obsolete. Lacinia is broad and obutse apically; distal comb is composed of numerous compact spines together with 4 long, isolated ones; there are 3 separating spines proximally. Galea is slightly arcuate along its outer margin and has a well defined pore at the middle near the margin; distal lobe is short, fairly constricted basally and provided with 4-5 long spines, which are arranged radially and jointed with a membrane; there are 2 basal setaceous sensillae, the proximal one is shorter. Labial palpus is seemingly 2 -segmented, there 
being no articulation between segment I and II; the last segment is narrower, about half as long as the basal one and its apex is neither verrucose nor spinose excepting a short apical spinula; setula $\alpha$ is robust and placed on inner side; $\beta$ is characteristically absent, while $\gamma$ is developed and placed close to $f ; a$ is strongly reduced and located near $t p$; $d$ is much reduced than $c$; $e$ is placed just in front of $t p$, but $h$ is absent; $m p$ is proximal from $f$ in position. Glossa is broadly rounded and with 2 pairs of compact spinulae. Prementum bears a short spine instead of the paired distal setae as the characteristic feature of Gyrophaenae; the median area is broad

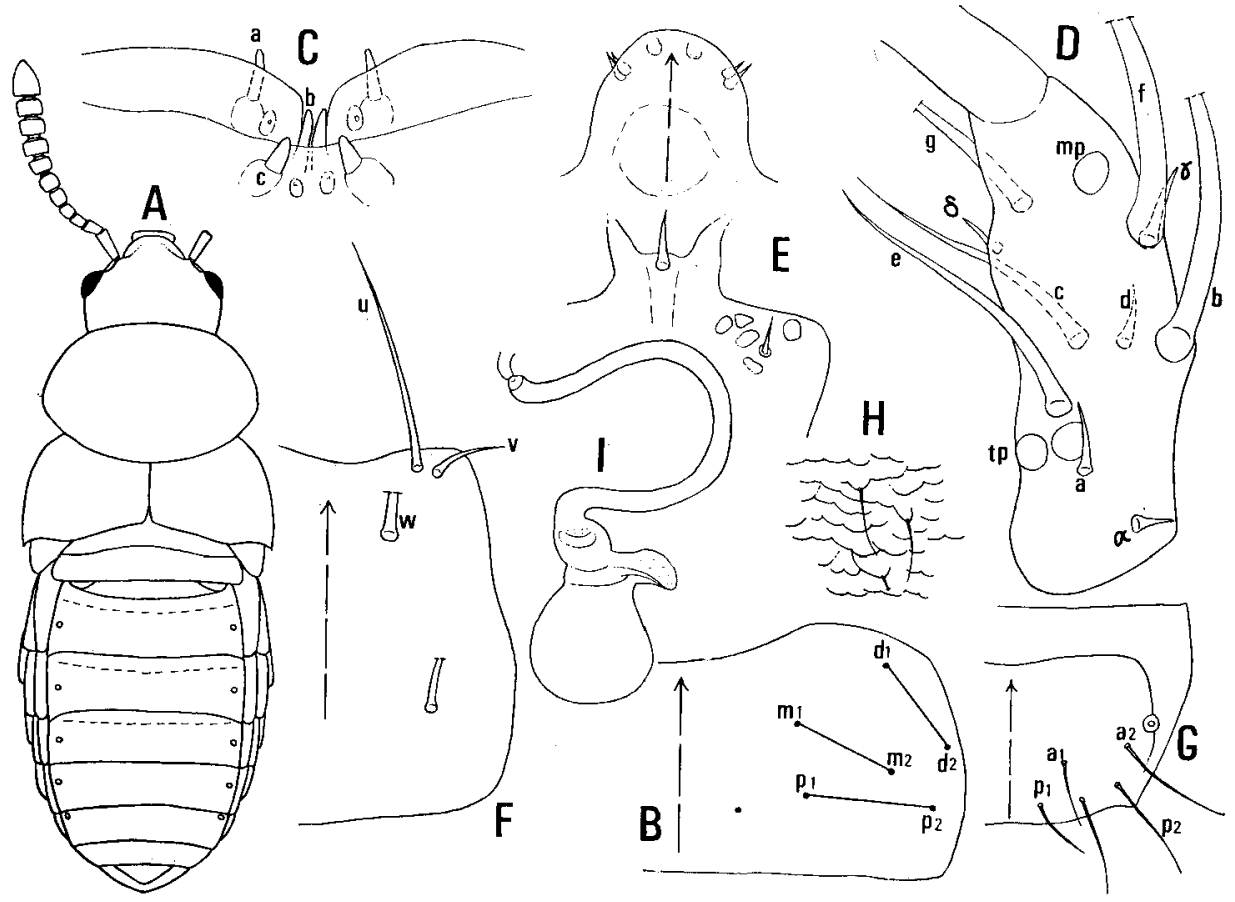

Fig. 1. Brachida brevipennis Bernhauer, 1938 from Seto. A, Habitus; B, Labral chaetotaxy; C, Labral margin; D, Setal arrangement of labial palpus (external view); E, Glossa and prementum; F, Mentum; G, Setae of terg. VIII; H, Microsculpture of terg. VIII; I, Spermatheca.

and without pseudopores; on the lateral area the real pores are poorly differentiated by the presence of coarsa pseudopores. Mentum is longer than broad and emarginate in front; seta $u$ is remote from the corner; $v$ is long and placed close to $u$; $w$ is normally located. Pronotum is convex above, transversely rounded and without depression; integument is minutely and sparsely punctured and with a distinct reticulation throughout. There is no distinct seta along the lateral margin. Elytron is slightly emarginate posteriorly and with distinct granules which are sparser laterally; there are conspicuous erecting setae along the lateral margin, they are usually 4 in number, the distalmost seta is exceptionally short. Metathoracic wing is absent. Abdomen is finely and obsoletely punctured and thickly pubescent laterally. Tergite 
VIII is feebly emarginate posteriorly; the principal setae are $5+5(2,3)$, among them seta $a-1, p-1$ are shorter than others; microsculpture of the terg. VIII is obscurely imbricate as in fig. H. Sternite VIII is rounded in the posterior margin and with $8+8$ principal setae. Ratio of tarsal segments as: 8:8:9:17.5 in fore-; 9:9:9.5:19.5 in mid-; 14:12:11.5:10:20 in hind-legs. Empodium of each tarsus is half as long as the claw.

Spermatheca is $0.25 \mathrm{~mm}$; the duct is slender and strongly curved; there is an obtuse laminate process at the neck of the bursa as in fig. I.

Length. $\quad 1.80 \mathrm{~mm}$ (Head long $0.28 \mathrm{~mm} \times$ wide $0.41 \mathrm{~mm}$; pronotum $0.38 \mathrm{~mm} \times$ $0.60 \mathrm{~mm}$; elytra $0.31 \mathrm{~mm} \times 0.72 \mathrm{~mm})$.

Specimens examined: 2q, Seto, Pref. Wakayama, 8. V. 1969, 14. IV. 1970, K. Sawada leg.

This species is near $B$. clara WEIse, 1877, but distinguished by the setal arrangement of labial palpus, longer glossa, longer distal and proximal rows of setae of labrum. The shape of spermatheca, roughly scultpured elytra with longer lateral setae are also characteristic to this species. Brachida brevipennis BERnHAUER, 1938 is described from Unzen, Pref. Nagasaki. This is the second report. In Seto it is rarely found from the litter of the pine forest in the campus.

\section{Tomoglossa cuspidata sp. $\mathrm{n}$.}

(Fig. 2)

§. Reddish brown and weakly shining. Head, pronotum, elytra and the distal half of abdomen are more or less infuscate; legs are paler than the antennae; the latter is darker toward the base. Head is ovate, deplanate above and with an obsolete depression in the middle; the surface is minutely and sparsely punctured and densely reticulate all over. Eye is much shorter than the post-ocular region and with pubescence fully twice as long as the diameter of a corner. Antenna is stout and with long setae; ratio of segments as: I $18 \times 11:$ II $12 \times 9:$ III $10 \times 10.5:$ IV $4 \times 12: \mathrm{X} 7 \times 15: \mathrm{XI} 20 \times 14$. Labrum is feebly emarginate; the principal setae are subequal in length, excepting the long $m-2 ; p-1$ is located close to the middle of the medial row; $d$ is an incurved long seta, anterior to $m-2$; the proximal row is more anteriorly located than in $T$. punctifoveata K. SAwADA, 1970; the secondary setae are reduced, $2+2$ in number. $a$-sensilla of labral margin is not setaceous, but entirely rounded and not protruded beyond the labral margin; $b$ is obtuse; $c$ is large and pointed. Left mandible is edentate; the right one bears minute serration along the inner margin, coarser proximally. Maxillary palpus is short; segment II is incrassate, much shorter than III and with a coarse network interiorly; III is rather fusiform, widest behind the middle and without an apical spinula. Lacinia is normally acuminate to form a trinagulum; the distal comb is large, composed of 8 long, compact spines, the proximal two of which would correspond to the isolated spines of usual 
forms. Galea bears 2 sensory pores, one on the middle and the other on apex; the distal lobe is small for the proximal sclerite, acuminate to pointed apex, uniformly ciliate and with only one setaceous basal sensilla. Labial palpus is distinctly 3segmented; segment I is fairly dilated distally; II is reduced, as long as broad; III is twice as long as II, feebly dilated toward the truncate apex, where a short spinula and a slender interior vesicle are present; the chaetotaxy is essentially as in T. punctifoveata, but setula $\gamma$ is more proximal, placed close to $\alpha$; seta $a$ is longer than $b$; $d$ is as long as $h$ and fairly distal in position. Glossa is broad and forked to the base into

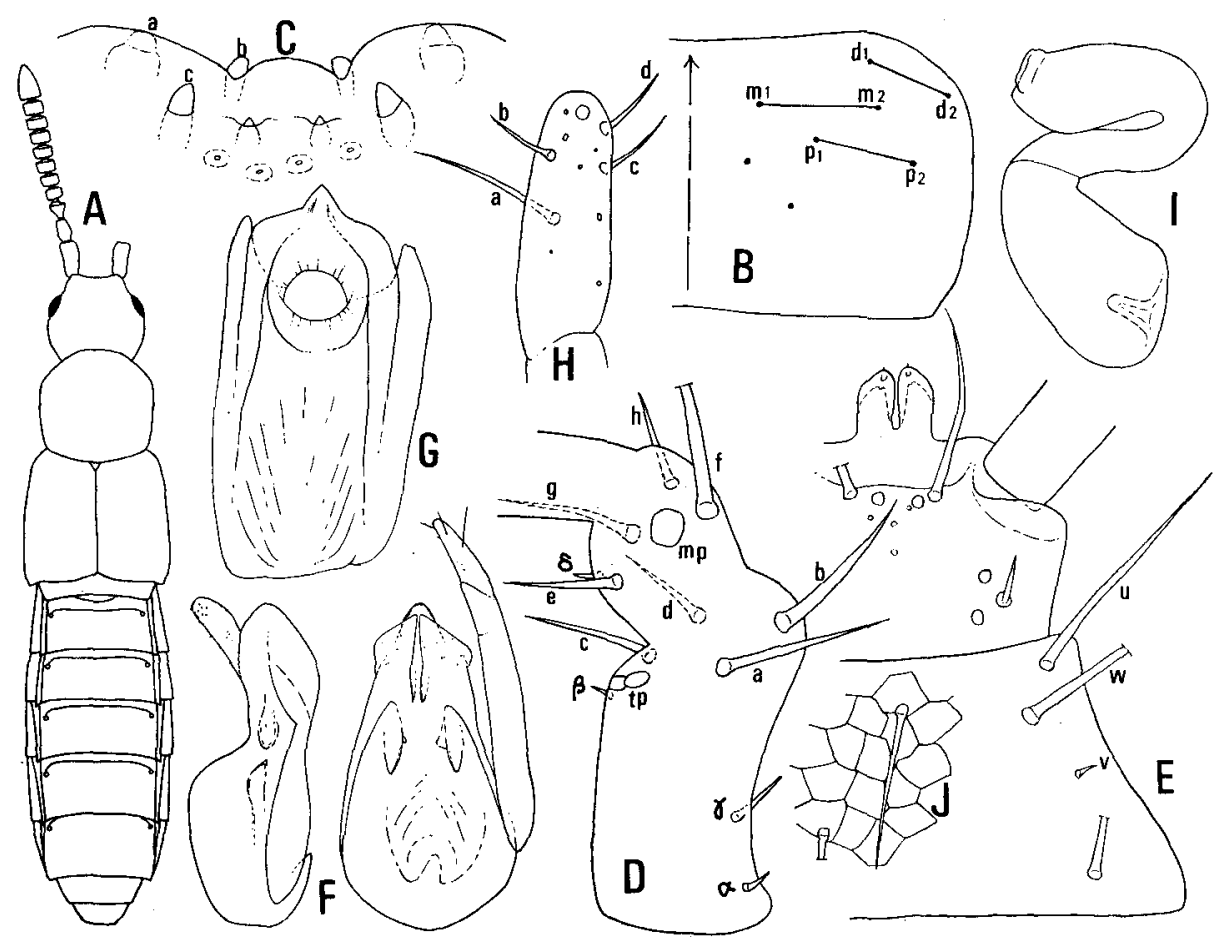

Fig. 2. Tomoglossa cuspidata sp. n. A, Habitus; B, Labral chaetotaxy; C, Labral margin; D, Setal arrangement of labial palpus (external view); E, Labium; F, Aedeagus (dors. and lat. view); G, Copulatory piece; H, The distal sclerite of left paramere; I, Spermatheca; J, Microsculpture of terg. VIII.

2 parallel arms, each arm is not narrowed distally and with a thickening interiorly; paired basal pores are removed on the sclerotized area between the distal setae of prementum. The median area of prementum is broad, with a few pseudopores; the lateral area is provided with up to 3 real pores and 1 setal pore arranged longitudinally, but their location is variable to some extent. Mentum is shallowly emarginate apically; seta $u$ is placed apart from the corner; $v$ is strongly reduced and dislocated proximally to the middle of the mentum. Pronotum is poorly convex anteriorly, obscurely depressed behind the middle and with an obsolete fovea near the basis; on 
the disc there are 6 setigerous, fovea-like punctures, 4 of which are anterior and 2 are posterior in position; the integument is punctured and sculptured as in the head; along the lateral margin 6 setae are present. Elytron is poorly sinuate posteriorly and more coarsely punctured than the pronotum. Metathoracic wing is fully developed. Abdomen is obsoletely punctured. Tergite VIII is broadly rounded and sinuate before the posterior corner; the principal setae are $5+5(2,1,2)$ and equally long; microsculpture on the middle is reticulate as in fig. J. Sternite VIII is arcuately produced behind and with $7+7(3,4)$ conspicuous setae on it. Ratio of tarsal segments as: 5:6:7:13 in fore; 5:6:6:6:12 in mid-; 9:8:8:8:15 in hind-legs. Empodium is not longer than the claw.

Aedeagus is $0.29 \mathrm{~mm}$ long. In dorsal view the median lobe is oblong ovate, with an obtuse apical lobe bowed ventrally and with large valves guarding the orifice. Copulatory piece is $0.085 \mathrm{~mm}$, rectangular in outline and with a short, but acute apical process; the annellus is of moderate size and placed at anterior one-third of the corpus; there is a broad, lamellate process beneath the corpus to form a prominent lobe on each side. Distal sclerite of paramere is oblong, poorly narrowed to obtuse apex; seta $a$ is the longest; $b, c, d$ are subequally short and subapical in position.

Length. $2.30 \mathrm{~mm}$ (Head long $0.26 \mathrm{~mm} \times$ wide $0.33 \mathrm{~mm}$; pronotum $0.40 \mathrm{~mm} \times$ $0.41 \mathrm{~mm}$; elytra $0.48 \mathrm{~mm} \times 0.50 \mathrm{~mm}$ ).

9. Spermatheca is $0.18 \mathrm{~mm}$ long, S-shaped and with a dilated end; the bursa is large, broadly truncate at the base and with a distinct umbilicus.

Holo-(ð), allo- and 8 ơ, 10 \% paratypes: Seto, Pref. Wakayama, 8. V. 1969, K. Sawada leg.

This species is closely allied to T. punctifoveata K. SAWADA, 1970, but distinguished by shorter glossa, more proximally removed setula $\gamma$ of labial palpus, broader copulatory piece with a cuspidate apex and by the narrower body with light colouration. In Tomoglossa a-sensilla of labral margin is reduced, although it is always long and setaceous in Ischnopoda, etc. The species was abundantly found under humus of the pine forest in the campus.

\section{Myrmecopora (s. str.) algarum (SHARP, 1874)}

(Fig. 3)

o. Rufotestaceous and moderately shining, but often infuscate, especially in the abdomen; antennae are uniformly pigmented; legs are lighter in colour. Head is thick dorso-ventrally, broadly deplanate above and with an obsolete, broad depression gradually narrowed behind; the integument is covered with fine, but dense, distinct punctures and without microsculpture. Eye is composed of small cornea and with fine pubescence, longer than the diameter of each cornea. Antenna is finely, densely pubescent; ratio of segments as: I $23 \times 11:$ II $16 \times 9:$ III $16: 10:$ IV $11 \times 11: \mathrm{X}$ 
$12 \times 13$ : XI $21 \times 12$. Labrum is not emarginate, but broadly crenate on the anterior margin; seta $p-2$ is shorter than $p-1$ and placed close to it; $m-2$ is laterally dislocated outside of the distal row; $d-1, d-2$ are subequally long; there are 2 large, elliptical sensillae anteriorly. $a$-sensilla of the labral margin is setaceous, not convergent; $b$ is quite obtuse; $c$ is unusually small, pointed and laterally behind $a$. Mandible is pointed

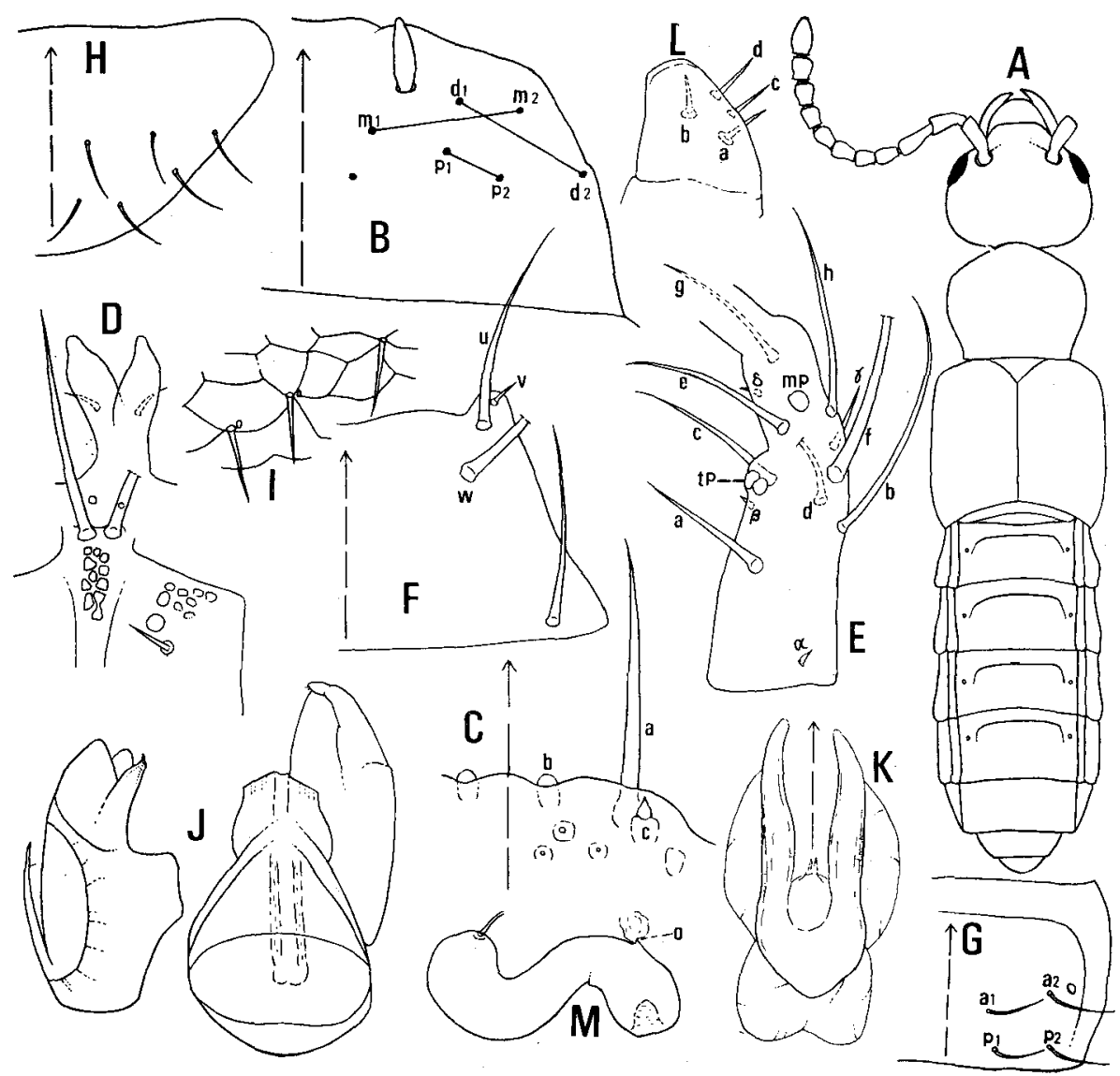

Fig. 3. Myrmecopora (s. str.) algarum (Sharp, 1874) from Seto. A, Habitus; B, Chaetotaxy of labrum; C, Labral margin; D, Labium; E, Labial palpus (right); F, Mentum; G, Terg. VIII; H, Stern. VIII; I, Microsculpture of terg. VIII; J, Aedeagus (dor. and lat. view); K, Copulatory piece (dor. view); L, Distal sclerite of paramere (left); M, Spermatheca.

on apex; the right one has a basal toothlet and short, rough dentation before it. Segment I of maxillary palpus is longer than wide, with a long spine externally; III is slender, gradually dilated distally; IV bears obsolete filamentous sensillae at the base and without apical spinula. Lacinia is as usual; the distal comb is consisting of 6 radial spines; there are ca. 6 fine spines on the base of the inner margin. Galea bears 3 sensory pores, 2 of them are in the middle and the other is apical in position; 
the distal lobe is moderate in size, obtuse on apex and with 2 reduced basal sensillae. Labial palpus is apparently 3 -segmented; setula $\alpha$ is broad; $\beta$ is normally reduced and placed close to $t p ; \gamma$ is located between $f$ and $h ; \delta$ is reduced and slightly distal from the level of $m p$; seta $a$ is proximally dislocated, far remote from $t p ; f$ is on the level of $t p ; e$ is anterior to $m p ; h$ is unusually removed proximally to the level of $m p$. Glossa is forked from the middle; each arm is narrowed and briefly produced on apex and bears a distinct spine interiorly. The median area of prementum is narrow, convergent behind; the pseudopores are aggregated and alike to the coarse reticulation; setal pore and one real pore of the lateral area are well differentiated, but others are seemingly mingled with pseudopores. Mentum is broadly emarginate in the middle of the anterior margin; the antero-lateral corner is briefly, but abruptly produced, where the setula $v$ is present; $u$ is normally long and subequal to the proximal seta in length, it is proximal to $v$ in position. Pronotum is gently convex above and usually with an indication of an obsolete sulcus along the middle. In some cases an obsolete lateral depression is observed before the base. The erecting lateral setae are insignificant; the surface is more finely punctured than on the head. Elytron is entirely deplanate above or evenly depressed in the most part; the integument is densely, rather coarsely punctured throughout and with microsculpture. Metathoracic wing is present, but fully depigmented. Ratio of tarsal segments as: 8:8:8:15 in fore-; 10:8:8:8:13 in mid-; 17:11:11.5:12:15 in hind-legs. Empodium is stout, blunt on apex and fairly longer than the claw. Abdomen is densely, rather asperately punctured, even on the tergite VI and VII. Tergite VIII is straight, not emarginate behind; there are 4 short principal setae, in which seta $a-2$ is lateral to the stigma; microsculpture of the basal part is represented as a kind of a coarse network, oblitarated in the anterior half of the tergite. Sternite VIII is acuminate to obtuse apex, with $6+6$ short principal setae.

Aedeagus $0.26 \mathrm{~mm}$ long. In dorsal view the median lobe is ovate, suddenly acuminate toward apex, where large, obliquely truncate valves are guarding the orifice. In lateral view the apical lobe is short and minutely produced at apex. Copulatory piece is rather small for the median lobe and bears a pair of long spiniform process embracing the annellus at the base; the annellus is obsoletely formed and with a short process interiorly; the suspensoria are entirely membraneous and lying beneath the copulatory piece. The distal sclerite of paramere is small, with $4+4$ subequally short setae, in which the seta $a, b$ are meidan in position.

Length. $2.40 \mathrm{~mm}$ (Head long $0.31 \mathrm{~mm} \times$ wide $0.43 \mathrm{~mm}$; pronotum $0.37 \mathrm{~mm} \times$ $0.41 \mathrm{~mm}$; elytra $0.51 \mathrm{~mm} \times 0.51 \mathrm{~mm})$.

ㅇ. Sternite VIII is provided with $5+5$ principal setae. Spermatheca is $0.15 \mathrm{~mm}$ long, S-shaped and with a broad duct; the bursa bears a robust umbilicus and a fine outburst ( $\mathrm{o}$ in fig. $\mathrm{M}$ ) may be a glandular appendix.

Specimens examined: 7 ex. Shingu, 14. IV. 1970, Dr. R. Yosi leg.; 9 ex. Kushimoto, 14. VI. 1970, Dr. R. Yosir leg.; 1 ex. Susami, 3. VII. 1970, K. Sawada 
leg; 2 ex. Seto, 7. V. 1969, K. Sawada leg.; 1 ex. Hatakejima in Seto, 8. V. 1969, K. SAwada leg.; 1 ex. Kirime, 15. V. 1970, K. SAwadA leg. all from Pref. Wakayama. 5 ex. Magarizaki, 6. V. 1970, Dr. R. Yosı leg.; 7 ex. Tororo, 6. V. 1970, Dr. R. Yosı leg. all from Amakusa, Pref. Kumamoto.

Myrmecopora SAULcy has a narrow neck, one-third to a half of the width of head. This character is one of the main generic difference to distinguish it from Ischnopoda $\mathrm{STEPHENs.} \mathrm{In} \mathrm{addition} \mathrm{to} \mathrm{it} \mathrm{the} \mathrm{presence} \mathrm{of} \mathrm{a} \mathrm{large} \mathrm{marginal} \mathrm{sensillae} \mathrm{of} \mathrm{labrum,}$ dislocation of seta $a$ of labial palpus and the shape of aedeagus without distinct formation of annellus may be regarded as characteristics. The species is fairly common among the wrack of the sea-shore.

\section{Ischnopoda (Coproceramius) atramentaria GYLLENHAL, 1810}

(Fig. 4)

8. Ground colour is piceous, with bronze reflection. The fore-parts are tinged with reddish brown; abdomen is intensely pigmented; antennae are brown and a little infuscate proximally; legs are paler. Head is broadly deplanate above, with a scarcely perceptible depression in the middle; the surface bears fine, moderately dense granules together with dense microsculpture. Eye is large, consisting of fine corneas and with dense pubescence fully twice as long as each cornea. Antenna is slender; ratio of segments as: I $12 \times 6.5:$ II $8 \times 4:$ III $6.5 \times 4:$ IV $5 \times 4.8: \mathrm{X} 6.5 \times 7: \mathrm{XI}$ $14 \times 7$. Labrum is clearly emarginate; seta $p-1$ is shorter than $p-2 ; d-1$ is equal to $d-2$ in length; the distal row is a little longer than the medial one; 2 short secondary setae are present. $a$-sensilla of labral margin is setaceous, convergent and recurved on apex; $b$ is broad, entirely rounded apically; $c$ is insignificant. Left mandible is edentate; the right one is more sharply pointed and with a well defined basal toothlet; prostheca is abruptly produced in the middle of the inner margin, where it is coarsely serrate. Maxillary palpus is slender as a whole; segment $I$ is as long as wide, with large paired pores; II is curved, with 2 setae behind the middle and 3 setae preapically; III is fairly longer than II, coarsely pubescent; IV is subulate and with a fine apical spinula and long basal filamentous sensillae. Lacinia is abruptly produced in the middle of its inner margin; the distal comb is composed of 6 distinct spines and with 2 large, isolated spines; there are ca. 4 recumbent spines before the base of the inner margin. Galea has a few, obsolete sensory pores in the middle; the distal lobe is very large, densely ciliate and with 2 basal sensillae, which are well defined and each with a short spinula. Labial palpus is slender; the last segment is fairly dilated toward the apex, where no apical spinula is present; the chaetotaxy is as in $I$. separata K. SAwADA, 1970; setula $r$ is just behind the seta $b$; $\delta$ is placed between $e$ and $g ; a$ is placed close to $t p ; c$ is much longer than $d ; h$ is on the level of $m p$. Glossa is narrow, constricted at the basis and forked from the anterior one-third into 2 short arms, usually the left arm is more reduced than the right. The meidan area of 
prementum is not constricted behind, with numerous pseudopores and long distal setae; the lateral area bears 2 real and 1 setal pore together with a few pseudopores. Mentum is emarginate; seta $u, v$ are placed close together at the corner; $v$ is well developed, subequal to one-third of $u$ in length; the proximal seta is quite basal in

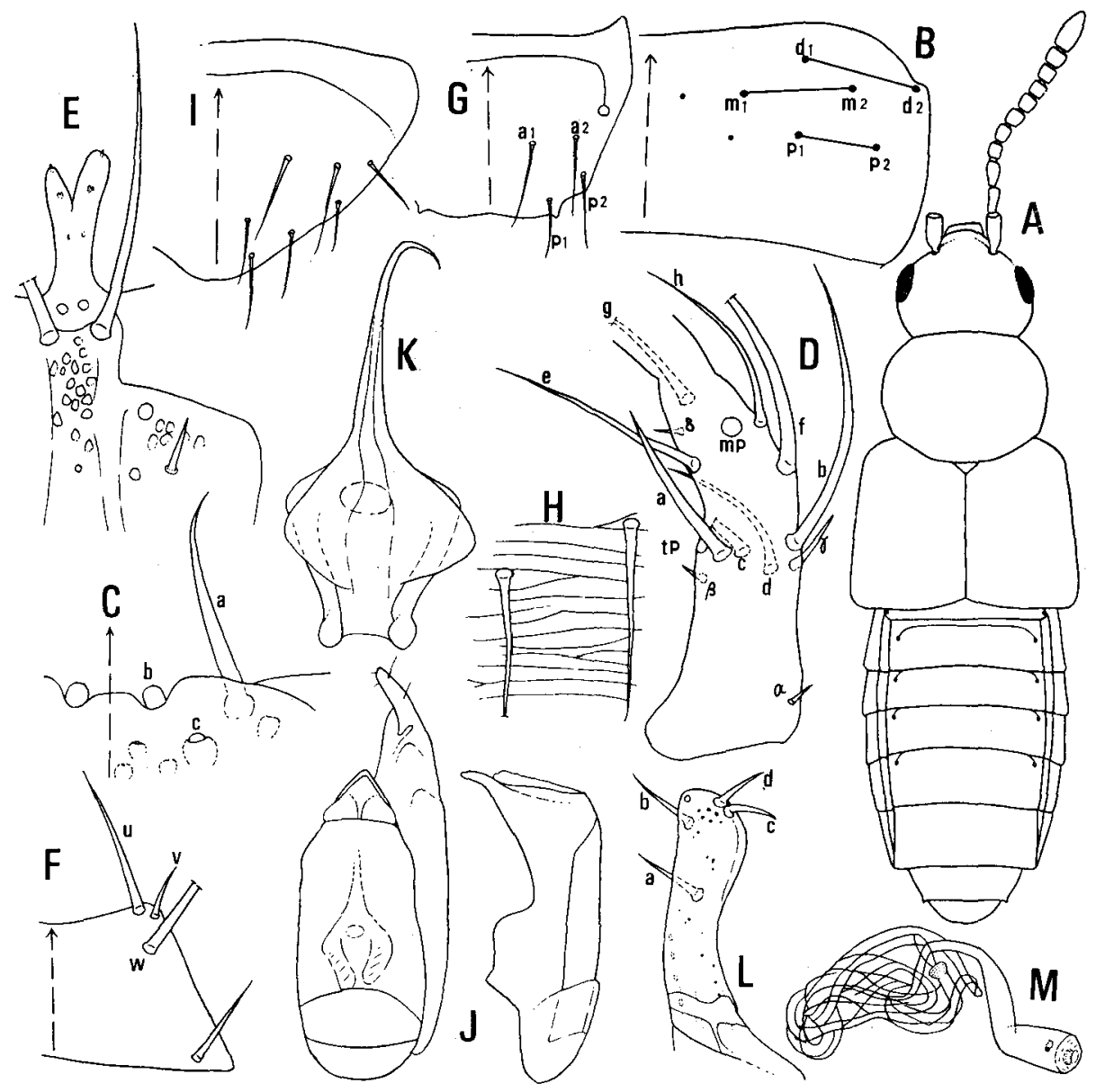

Fig. 4. Ischnopoda (Coproceramius) atramentaria (Gyllenhal, 1810) from Seto. A, Habitus; B, Labral chaetotaxy; C, Labral margin; D, Setal arrangemet of labial palpus (right); E, Labium; F, Mentum; G, Tergite VIII; H, Microsculpture of terg. VIII; I, Stern. VIII; J, Aedeagus (dors. and lat. view); K, Copulatory piece (dors. view); L, Distal sclerite of paramere (left); M, Spermatheca.

position. Pronotum is gently convex above, declivous antero-externally, with an obsolete depression before the base and a broad sinuation on each side of the hind margin; the integument is densely asperate, with quite obscure microsculpture; there are 5 erecting lateral setae, among them the 1 st and the $3 r d$ are much longer than others. Elytron is not emarginate posteriorly and equal to the pronotum in punctuation and 
microsculpture. Metathoracic wing is present. Ratio of tarsal segments as: $7: 8: 9$ : 23 in fore-; 8:10:10:11:22 in mid-;12:12:12.5:12.5:33 in hind-legs. Empodium of all tarsi is reaching the middle of the claw. Abdomen is finely and densely punctured, the punctures are fewer toward the extremity. Tergite VIII is nearly truncate behind and with a slightly produced lateral corner; seta $a-1$ is longer than $p-1$, which is placed near the lateral corner; microsculpture is transversely striated. Sternite VIII is acuminate to obtuse apex, with $7+7$ principal setae.

Aedeagus $0.43 \mathrm{~mm}$ long. In dorsal view the median lobe is parallel-sided in the middle, slightly constricted anteriorly and acuminate to triangular apex; the valve is well-developed and pigmented. In lateral view the median lobe is dilated from the middle and broadly truncate on apex; the short apical lobe is sinuately produced. Copulatory piece is near $I$. separata, but the dilated portion of the corpus is poorly sclerotized and obliquely arised covering the pigmented lower apophysis; the apical process is styliform, longer than the corpus and upwardly curved on apex; the suspensorium is entirely membraneous and seemingly above the corpus in repose. Paramere is narrowly elongate, broadly sinuate on its inner margin; the setae are subequally short; $a, b$ are separating, while $c, d$ are placed close together on apex.

오. Tergite VIII is clearly sinuate behind. Sternite VIII is subtruncate behind and with $6+6$ principal setae. Spermatheca is $0.41 \mathrm{~mm}$ in diameter; the duct is extemely complicate as in fig. $\mathrm{M}$; the bursa is elongate, and bears a reduced umbilicus and a small outburst near the base.

Specimens examined: 10 ex. Seto, 7. V. 1969, K. SAwada leg., 2 ex. Hatakejima in Seto, 8. V. 1969, K. Sawada leg. all in Pref. Wakayama.

Distribution: Palearctic Region, West Africa.

The species is conspicuous with the unusually reduced, obtuse $c$-sensilla of labral margin and with the complicate form of spermatheca. Seto specimens agree well with the description of Ganglbauer, 1895. The figures given by Hansen, 1954 serve well to identify the species. The presence of this Palearctic species from Japan is already reported in BERNHAUER, 1907. The species is taken under the cadaver of a dog on the sandy beach.

\section{Ischnopoda (Chaetida) multipunctata sp. n.}

(Fig. 5)

0. Subopaque by the presence of the distinct microsculpture. Deeply pigmented brown excepting the rufescent basal part of abdomen; antennae are dark in colour, infuscate proximally, excepting the basalmost segment. Head is gently convex above, with an obsolete median depression not reaching the base; the integument is densely punctured and scultpured. Eye is large, composed of very fine corneas and with sparse pubescence fully twice as long as the diameter of each cornea. Antenna is scarcely dilated distally; ratio of segments as: I $19 \times 8:$ II $13 \times 6$ : III $14 \times$ 
$7:$ IV $11 \times 7:$ X $8 \times 9:$ XI $17 \times 9$. Labrum is distinctly emarginate anteriorly; seta $p-1$ is equal to $p-2$ in length; $m-2$ is as long as $m-1$ and palced on the distal row; there are 2 long secondary setae, fully as long as the proximal setae, but much paler; the proximal row is very short compared to 2 other rows. $a$-sensilla of the labral margin is setaceous, separating from the other by its own length; $b$ is broadly

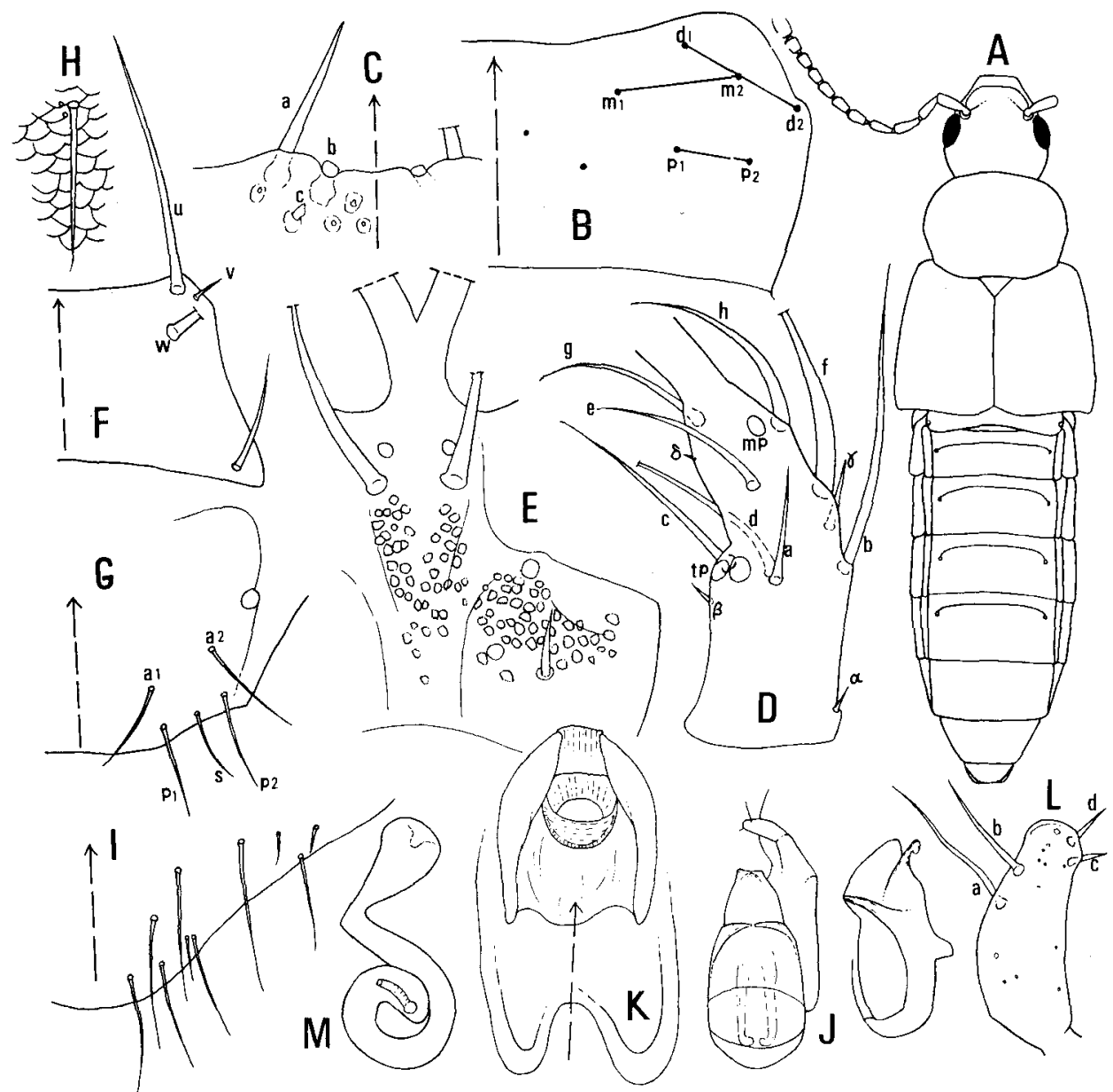

Fig. 5. Ischnopoda (Chaetida) multipunctata sp. n. A, Habitus; B, Labrum; C, Labral margin; D, Right labial palpus; E, Labium; F, Mentum; G, Terg. VIII; H, Microsculpture of terg. VIII; I, Stern. VIII; J, Aedeagus (dors. and lat. view); K, Copulatory piece (dors. view); L, Distal sclerite of the left paramere; M, Spermatheca.

truncate apically; $c$ is more reduced than usual, smaller than $b$. Mandible is acuminate to the acute, curved apex; the right one has a basal toothlet and minutely serrate before it. Maxillary palpus is slender as a whole; segment $\mathbf{I}$ is longer than broad, with an extremely short setula; II is a little shorter than III, impunctate exteriorly, and with a distinct umbilicate microsculpture; III is not broader than II 
and densely pubescent; IV is not narrowed toward apex, with a hyaline spinula and obliterate basal sensillae. Lacinia is long, dilated in the middle of the inner margin, where it is densely ciliate; the distal comb is consisting of 6 spines and 2 isolated basal spines, closely placed to the former; there are ca. 5 large, half-recumbent spines near the base. Galea is long and with numerous sensory pores and a well defined apical pore; the distal lobe is large, acuminate to narrowly pointed apex, very finely ciliate and with reduced setaceous basal sensillae. Labial palpus is distinctly 3segmented; setula $\alpha$ is standing on a minute process; $\beta$ is placed behind $t p ; \gamma$ is proximal to $f ; \delta$ is reduced and far remote from $e$; seta $a$ is much shorter than $b$; $c, d$ are subequal in length; $f$ is fairly broad and on the same level with $e ; h$ is close to $m p$. Glossa is typical of the genus; each arm with an obtuse apical spinula. The median area of prementum is narrower than the lateral area and beset with unusually numerous, irregular pseudopores; the lateral area bears 2 real and 1 setal pores obscured by the presence of numerous pseudopores as in the median area. Mentum is lightly emarginate anteriorly and with numerous fine pores; seta $u$ is placed on the corner; $v$ is short, close to $u$; $w$ is remote from $u$; the proximal seta is shorter than $u$. Pronotum is gently convex above and with a faint median depression more or less dilated toward the base; each lateral margin is straight on the basal half and retracted behind to form a conspicuous basal corner; from 4 erecting lateral setae 2 posterior ones are strongly reduced; the integument is very densely sculptured and pubescent as on the head to give a sericeous appearance. Elytron is scarcely sinuate posteriorly and with dense, fine punctures throughout, each of them accompanied mostly by a micropore. Metathoracic wing is fully developed. Ratio of tarsal segments as: 14:14:15:38 in fore-: 17:19:20:20:38 in mid-; 22:26:25:25:51 in hind-legs. Empodium of all tarsi is unusually reduced, much shorter than the claw. Abdomen is coarsely punctured distally and devoid of distinct punctures on proximal segments. Tergite VIII is faintly emarginate in the middle of the posterior margin; among 5 principal setae the intermediate seta ( $\mathrm{s}$ in fig. $\mathrm{G}$ ) is shorter and variable in location; $a-2$ is remote from the stigma; microsculpture is of imbricate type. Sternite VIII is acuminate to obtuse apex and with $10+10$ long and short principal setae.

Aedeagus is $0.65 \mathrm{~mm}$. In dorsal view the median lobe is broad anteriorly and then graudally narrowed to the truncate apex. In lateral view the apical lobe is not extending beyond the median lobe and distinctly hooked ventrally to form an apical thickening. Copulatory piece is peculiar, without apical process and truncate on the opposite end; the suspensorium is well sclerotized, placed behind the copulatory piece and decply emarginate in the posterior margin. Paramere is moderate in size; the distal sclerite is oblong; seta $a, b$ are long and rather apical on position; $c, d$ are subequally short and placed close together.

Length. $\quad 5.50 \mathrm{~mm}$ (Head long $0.74 \mathrm{~mm} \times$ wide $0.76 \mathrm{~mm}$; pronotum $0.76 \mathrm{~mm}$ $\times 0.91 \mathrm{~mm}$; elytra $1.10 \mathrm{~mm} \times 1.35 \mathrm{~mm}$ ).

ㅇ. Sternite VIII is almost as in the male. Spermetheca is $0.34 \mathrm{~mm}$; the duct 
is entirely coiled; the bursa is convergent apically forming a narrow neck.

Holotype (ô): Seto, Pref. Wakayama, 7. V. 1970, K. Sawada leg. Allotype: Yuigahama in Kamakura, Pref. Kanagawa, 30. V. 1970, Dr. R. Yosir leg.

The species is distinguished from $I$. (C.) subantennata (CAMERon, 1933) by the shorter antennae and rougher elytra. It differs also from $I$. (C.) subasperata (BrenHAUER, 1907) by the broader head and longer elytra. The surface structure of prementum seems to be very conspicuous.

\section{Ischnopoda (Philhygra) ushio sp. n.}

(Fig. 6)

3. Brown and subopaque excepting the shining abdomen. Head is often infuscate; elytra are rufescent distally; abdomen is nearly black toward the extremity; antennae are brown, often paler at the base; legs are lighter in colour. Head is ovate, rounded laterally and obviously depressed in the middle of epicranium; frons bears some 5 pairs of erecting, strong setae; the integument is nearly impunctate and strongly coriaceous. Eye besets with long pubescence. Antenna is slender; ratio of segments as: I $21 \times 9.5:$ II $14 \times 7.5:$ III $11 \times 8:$ IV $8 \times 9: \mathrm{X} 7 \times 12: \mathrm{XI} 17 \times 12$. Labrum is feebly emarginate; the setal arrangement is as in $I$. (Hygroecia) spinula $\mathrm{K}$. SAwada, 1970 , but the seta $m-2$ is laterally dislocated beyond the distal row; the proximal row is the shortest; 3 secondary setae are usually present. $a$-sensilla of labral margin is setaceous, convergent; $b$ is narrow and briefly pointed on apex; $c$ is subdivided faintly. The right mandible is serrulate, with a basal toothlet; the left one is edentate. Maxillary palpus is long and with coarse microsculpture; segment $\mathbf{I}$ is emarginate anteriorly and with a minute setula ventrally; II is slender, curved and with an impunctate surface; III is gently dilated toward the middle and with numerous pubescence; IV is subulate as usual, dilated distally and with an apical spinula and well-developed basal sensillae. Lacinia is produced inside; the distal comb is large, composed of 6 pointed spines radially arranged, the apicalmost one is shorter than others; 2 isolated spines ( $\mathrm{o}$ in fig. $\mathrm{E}$ ) are close together and normal in position. Galea is curved, with some apical pores and basal microsculpture; the distal lobe is large, acuminate to pointed apex and with strongly reduced basal sensillae. Labial palpus is typical of the genus; setula $\beta$ is remote from $t p$, but is small and perceptible only with high magnification; $\gamma$ is normally long and hidden by the seta $b ; \delta$ is just so reduced as $\beta$ and placed distal to $e ; a, d$ are much shorter than $b, c ; f$ is located behind $m p$. Glossa is forked to the middle and diverging into 2 blunt arms; the basal pores are well defined. The median area of prementum is narrower than the lateral area and with obsolete pseudopores; 2 real pores and 1 setal pore are present on the latter. Mentum is poorly emarginate; seta $u$ is placed near the anterior margin; $v$ is situated on the corner; the proximal seta ( $\mathrm{x}$ in fig. $\mathrm{G}$ ) is fairly shorter than $u$. Pronotum is broadly and obsoletely depressed in the middle; among 3 erecting lateral setae the 
basalmost one is the shortest; the integument is densely, but finely punctured and with extremely fine microsculpture. Elytron is scarcely emarginate posteriorly and densely punctured as in the pronotum. Abdomen is finely and obsoletely punctured. Tergite VIII is not acuminate behind and with the truncate posterior margin which is indistinctly crenate in its full length; there are $5+5$ principal setae arranged as

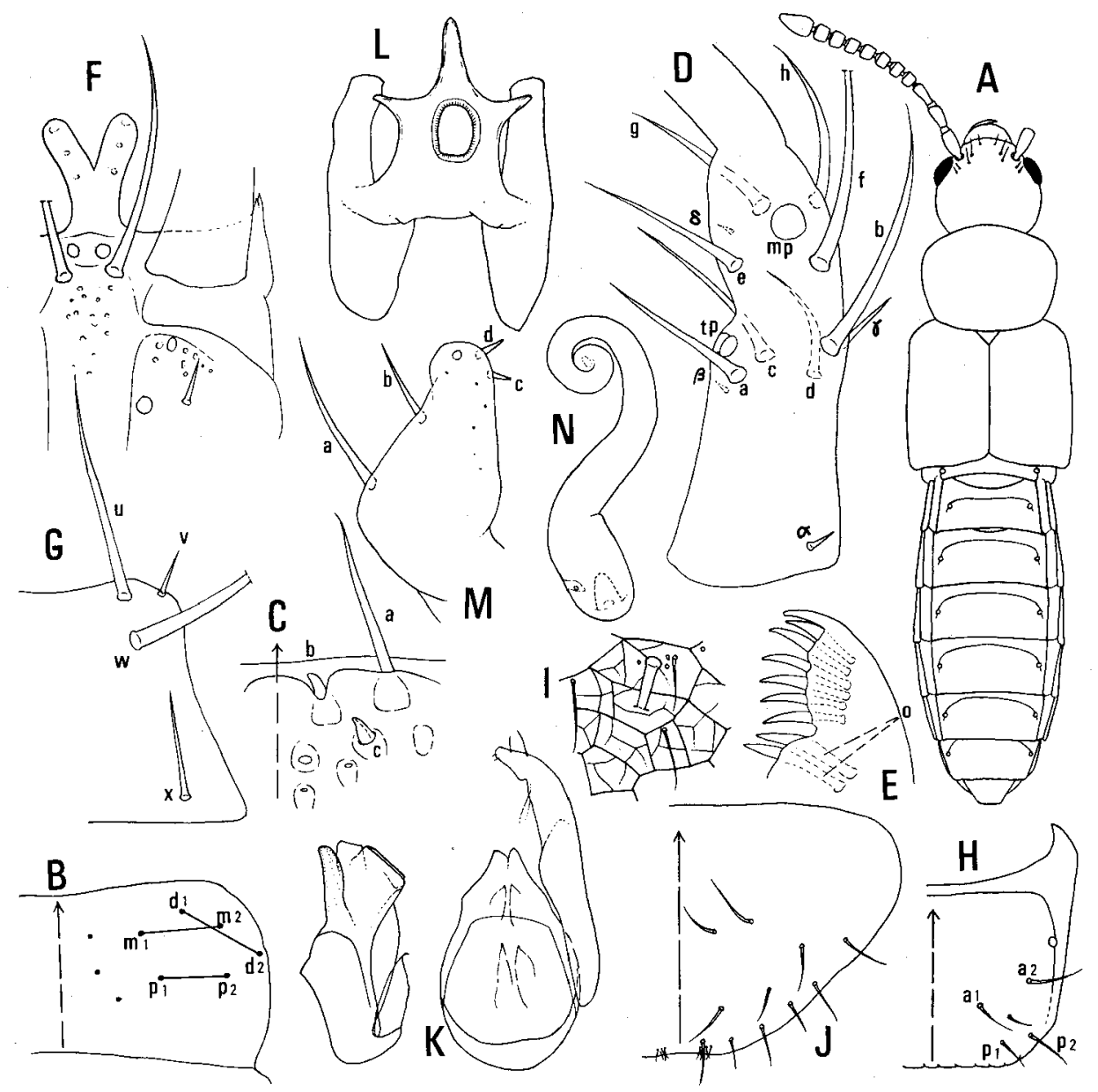

Fig. 6. Ischnopoda (Philhygra) ushio sp. n. A, Habitus; B, Labral chaetotaxy; C, Labral margin; D, Labial palpus; E, Distal comb of lacinia; F, Labium; G, Mentum; H, Terg. VIII; L, Microsculpture of terg. VIII; J, Stern. VIII; K, Aedeagus (dors. and lat. view) : L, Copulatory piece (vent. view): M, Distal sclerite of the left paramere; N, Spermatheca.

in fig. $\mathrm{H}$, whose intermediate seta is the shortest; $p-1, p-2$ are placed on the lateral corner of the tergite; microsculpture of the middle is reticular, the coarse irregular primary reticulation is accentuated by the larger secondary reticulum. Sternite VIII is acuminate and with a faintly sinuate apex and on each side of it a tuft of minute setulae is present; up to $11+11$ principal setae are observed. Ratio of tarsal 
segments as: $11: 11: 11: 28$ in fore-; $11: 11: 12: 12: 26$ in mid-; $15: 15: 16: 16: 30$ in hindlegs. Empodium of all tarsi is much longer than the claw.

Aedeagus is $0.30 \mathrm{~mm}$ long. In dorsal view the median lobe is ovate and acuminate to the bifid apex. In lateral view the apical lobe is obtuse and straight. Copulatory piece is strongly modified, it is tricaspidate with a blunt apical and a pair of lateral process, whose apex is considerably raised upwards; the suspensorium is sclerotized, elongate and connected above the copulatory piece.

Length. $1.90 \mathrm{~mm}$ (Head long $0.32 \mathrm{~mm} \times$ wide $0.36 \mathrm{~mm}$; pronotum $0.36 \mathrm{~mm}$ $\times 0.40 \mathrm{~mm}$; elytra $0.48 \mathrm{~mm} \times 0.54 \mathrm{~mm})$.

ㅇ. In contrast to males the head is not modified leaving an obsolete depression along the middle. Furthermore the integument bears distinct, dense punctures, excepting the depressed portion of the head. Tergite VIII is not crenate, but faintly emarginate in the middle of the posterior margin. Sternite VIII is as in the male, but the tuft of setulae of the posterior margin is quite absent. Spermatheca is $0.27 \mathrm{~mm}$ long; the duct is compactly coiled up; the bursa is oblong and bears a robust umbilicus and a fine accessory pore near the base.

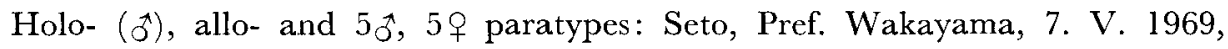
K. Sawada leg.

Specimens examined: 4 ex. Hatakejima in Seto, 8. V. 1969, K. Sawada leg., 2 ex. Shingu, 14. IV. 1970, Dr. R. Yosir leg., 3 ex. Hashikuiiwa in Kushimoto, 14. IV. 1970, Dr. R. Yosı leg., all from Pref. Wakayama. 3 ex. Nishikigaura in Atami, Pref. Kanagawa, 29. V. 1970, Dr. R. YosII leg., 14 ex. Wakasa-Takahama, Pref. Kyoto, 20. V. 1969, K. Sawada leg., I ex. Miyajima, Pref. Hiroshima, 9. V. 1970, Dr. R. Yosir leg., 15 ex. Shikanoshima in Hakata, Pref. Fukuoka, 8. V. 1970, Dr. R. Yosi leg., 4 ex. Hara in Shimabara, Pref. Kumamoto, 7. V. 1970, Dr. R. Yosi leg., 6 ex. Takahama, 6. V. 1970, Dr. R. Yosir leg., 5 ex. Tororo, 5. V. 1970, Dr. R. Yosil leg., 1 ex. Magarizaki, 6. V. 1970, Dr. R. Yosi leg., all from Pref. Kumamoto.

Distribution: Japan (Honshu, Kyushu).

This species differs from the description of I. niponensis (SHARP, 1888) by the remarkably modified head of the male, narrower pronotum and smaller body size, etc. The specific name "ushio" means a tide in Japanese. This species seems to be the commonest inhabitant of Aleocharinae of the wrack being found from various places of the western Japan.

\section{Ischnopoda (Dinaraea) tokiokai sp. $\mathrm{n}$.}

(Fig. 7)

3. Fuscous and shining, but the anterior part of abdomen are rufescent; antennae are uniformly brownish; legs are lighter in colour. Head is gently convex above, shallowly depressed on the middle and finely but densely punctured all over; the interspace is scattered with micropores and microsculpture. Eye is large, longer 
than the post-ocular region and with long pubescence. Antenna is dilated distally; ratio of segments as: I $20 \times 9:$ II $14 \times 7.3:$ III $11 \times 7.5:$ IV $10 \times 8:$ X $9 \times 12: \mathrm{XI}$ $24 \times 12$. Labrum is not emarginate in the fore margin and the principal setae are confined to the anterior half of the labrum; seta $p-1$ is much longer than $p-2 ; m-2$ is placed on the distal row; a long secondary seta is always present. $a$-sensilla is robust and converging; $b$ is reduced, broadly truncate apically, not reaching beyond the margin; $c$ is broadly rounded. Mandible is narrowly pointed and with many pores basally; the right one bears a basal toothlet. Maxillary palpus is slender; segment $I$ is very small and with a setula; II is gradually dilated distally and with a coarse reticulation exteriorly; III is much longer than the preceding and with long pubescence; IV is subulate, but dilated on apex and with an apical spinula. Lacinia is abruptly produced in the middle of the inner margin to form a triangular dilation; the distal comb is composed of 6 distinct spines becoming longer basally; 2 isolated spines are well differentiated behind the distal comb. Galea is narrow, poorly rounded along its outer margin and without any sensory pores in the middle; the distal lobe is welldeveloped, acuminate to the obtuse apex and with reduced basal sensillae having no setulae on it. Labial palpus is indistinctly 3-segmented; the last segment is strikingly clavate apically, where it is verrucose and with a small apical vesicle; setula $\alpha$ is longer than usual; $\beta$ is strongly reduced behind $t p ; \gamma$ is shorter than usual and placed just before $f ; \delta$ is so much reduced as $\beta$ and situated near $g$; seta $a$ is subqual to $b$ in length and proximally dislocated so that it is far remote from $t p ; e$ is proximal to $f$ in position; $h$ is on the same level with $m p$. Glossa is forked and constricted basally; the arm is not narrowed distally and rounded on apex. The median area of prementum is fairly narrower than the lateral area and with obsolete microsculpture; 2 real and 1 setal pores are poorly differentiated. Mentum is emarginate anteriorly: there are numerous coarse setae on it; seta $u$ is placed on the corner; $v$ is relatively small: $w$ is longer than $u$ and normal in position. Pronotum is broadly deplanate above and with an obsolete median depression; the posterior corner is rather angulate; the erecting lateral setae are 4 in number, all inconspicuous; the surface is obsoletely punctured and distinctly sculptured as in the head. Elytron is not emarginate, but faintly sinuate posteriorly and minutely but densely punctuated. Metathoracic wing is present. Ratio of tarsal segments as: $6: 6: 7: 18$ in fore-; 7:8:8:8:18 in mid-; 11:10; 10:10:21 in hind-legs. Empodium is absent. Abdomen is similarly punctured, but obliterate toward the extremity. Tergite VIII is entirely truncate in the posterior margin and not modified; the microsculpture of the middle is imbricate as in fig. $\mathrm{H}$; from 4 principal setae $a-2$ is remote from the stigma and equal to $a-1$ in length. Sternite VIII is acuminate to obtuse apex, narrowly transparent along the posterior margin and with $8+8$ long principal setae.

Aedeagus is $0.28 \mathrm{~mm}$ long. In dorsal view the median lobe is elongate and strongly sclerotized in most part; the lateral margin of the anterior half is parallel and then abruptly narrowed forming a triangular apical lobe. In lateral view 
the apical lobe is fairly protruded beyond the median lobe and bears a median carinula with an acute incision. Copulatory piece is remarkably modified, a pair of well-developed lateral expansion reminds us the seed of a maple tree, but the

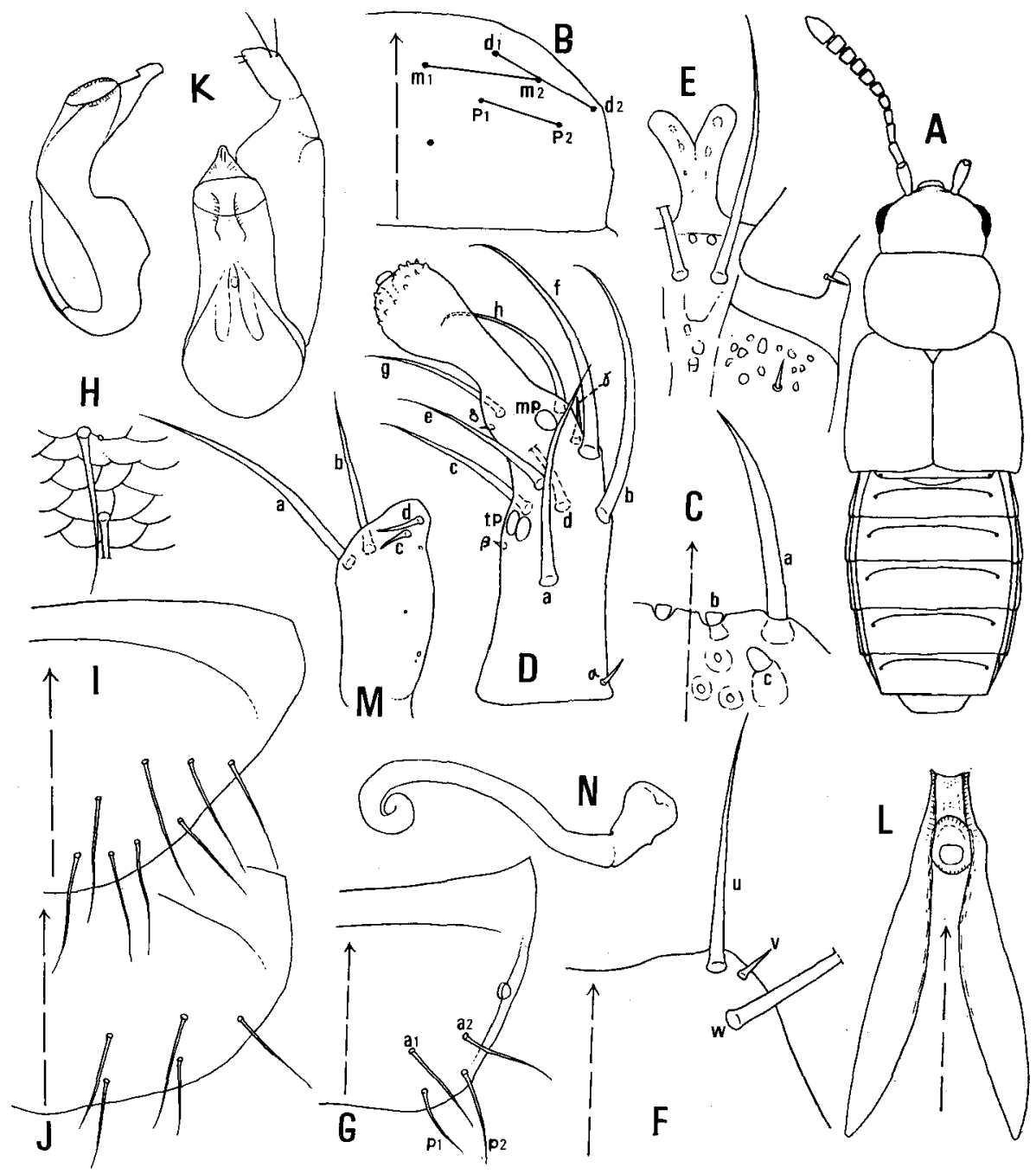

Fig. 7. Ischnopoda (Dinaraea) tokiokai sp. n. A, Habitus; B, Chaetotaxy of labrum; C, Labral margin; D, Right labial palpus; E, Labium; F, Mentum; G, Terg. VIII; H, Microsculpture of terg. VIII; I, đ Stern. VIII ; J, O Stern. VIII; K, Aedeagus (dors. and lat. view); L, Copulatory piece (vent. view) $\mathbf{M}$, Distal sclerite of the left paramere; $N$. Spermatheca.

anterior part before the annellus is strongly abbreviated and truncate apically. The distal sclerite of paramere is broad; seta $a$ is fairly longer than $b$ and located close to it; $c, d$ are small and apical in position.

Length. $2.20 \mathrm{~mm}$ (Head long $0.40 \mathrm{~mm} \times$ wide $0.42 \mathrm{~mm}$; pronotum $0.40 \mathrm{~mm} \times$ 
$0.50 \mathrm{~mm}$ : elytra $0.55 \mathrm{~mm} \times 0.75 \mathrm{~mm}$ ).

ㅇ. Sternite VIII is fairly shorter than in males, without narrow transparent zone along the margin and there is a distinct reduction of principal setae to $5+5$. Spermetheca is $0.22 \mathrm{~mm}$; the duct is narrow, nearly straight and briefly coiled up apically; the bursa is small and with a faint umbilicus.

Holo- $\left(\delta^{*}\right)$ and allotype: Seto, Pref. Wakayama, 7. V. 1969, K. Sawada leg., 4 paratypes: Hashikuiiwa in Kushimoto, Pref. Wakayama, 4. IV. 1970, Dr. R. Yosir leg.

Specimens examined: 10 ex. Hashikuiiwa, in Kushimoto, 16. V. 1970, K. SAwada leg., 2 ex. Shingu, 14. IV. 1970, Dr. R. Yosi leg., 11 ex. Mirozu, 3. VII. 1970. K. SAwada leg., 12 ex. Hinomisaki, 5. V. 1970, K. SAwada leg., all from Pref. Wakayama. 1 ex. Hichirigahama in Kamakura, Pref. Kanagawa, 30. V. 1970, Dr. R. Yosir leg., 1 ex. Wakasa-Takahama, Pref. Kyoto, 20. V. 1969, K. SAwada leg., 5 ex. Magarizaki, 6. 1970, Dr. R. Yosi leg., 2 ex. Tororo, 5. V. 1970, Dr. R. Yosi leg., all from Amakusa, Pref. Kumamoto.

Distribution: Japan (Honshu, Kyushu).

This species is allied to the European I. (D.) linearis (Gravenhorst, 1802) (sensu Ganglbauer, 1895), by the shorter 3rd segment of antennae, longer elytra without posterior emargination and by the shorter body length. This is the common inhabitant of the wrack next to $I$. ushio sp. n. With my best wishes the species is dedicated to Prof. T. Tokioka of the Seto Marine Biological Laboratory.

\section{Aleochara (Emplenota) fucicola SHARP, 1874}

(Fig. 8)

๙. Ground colour is almost black, but subopaque by dense microsculptre on the fore-parts. Antennae are also intensively pigmented; legs are somewhat paler. Head is gently convex above, coarsely and densely punctured leaving a median impunctate area. Eye is large, composed of fine cornea and with a few short, blund setulae. Antenna is stout and short; ratio of segments as; I $33 \times 13$ : II $21 \times 11$ : III $22 \times 13:$ IV $13 \times 14: \mathrm{X} 13 \times 18: \mathrm{XI} 28 \times 17$. Labrum is lightly emarginate; loci and length of principal setae are somewhat variable; $p-1, p-2$ are usually subequal in length; $m-2$ is variable in length; $d-1$ is nearly straight; the distal row is the shortest, much shorter than the proximal row; the secondary setae are long, similar to the principal setae. $a$-sensilla of the labral margin is long, setaceous; $b$ is very thin and elongate, acutely pointed and produced beyond the margin; $c$ is insignificant. Left mandible is infolded and thick apically, whereas the right one is simply pointed and obsoletely crenate along the inner margin; prostheca is evenly ciliate on its full length. Segment I of maxillary palpus is not transverse, with a seta placed close to the paired apical pores; II is impunctae for the most part, with an obsolete reticulation in the middle; III is gradually dilated distally and coarsely spinose; IV is 
faintly subsegmented before apex and with many long filamentous sensillae at the base. Lacinia is well sclerotized; the distal comb is consisting of about 12 distinct spines; among them the apicalmost one is smaller than others; the basal spines are also smaller

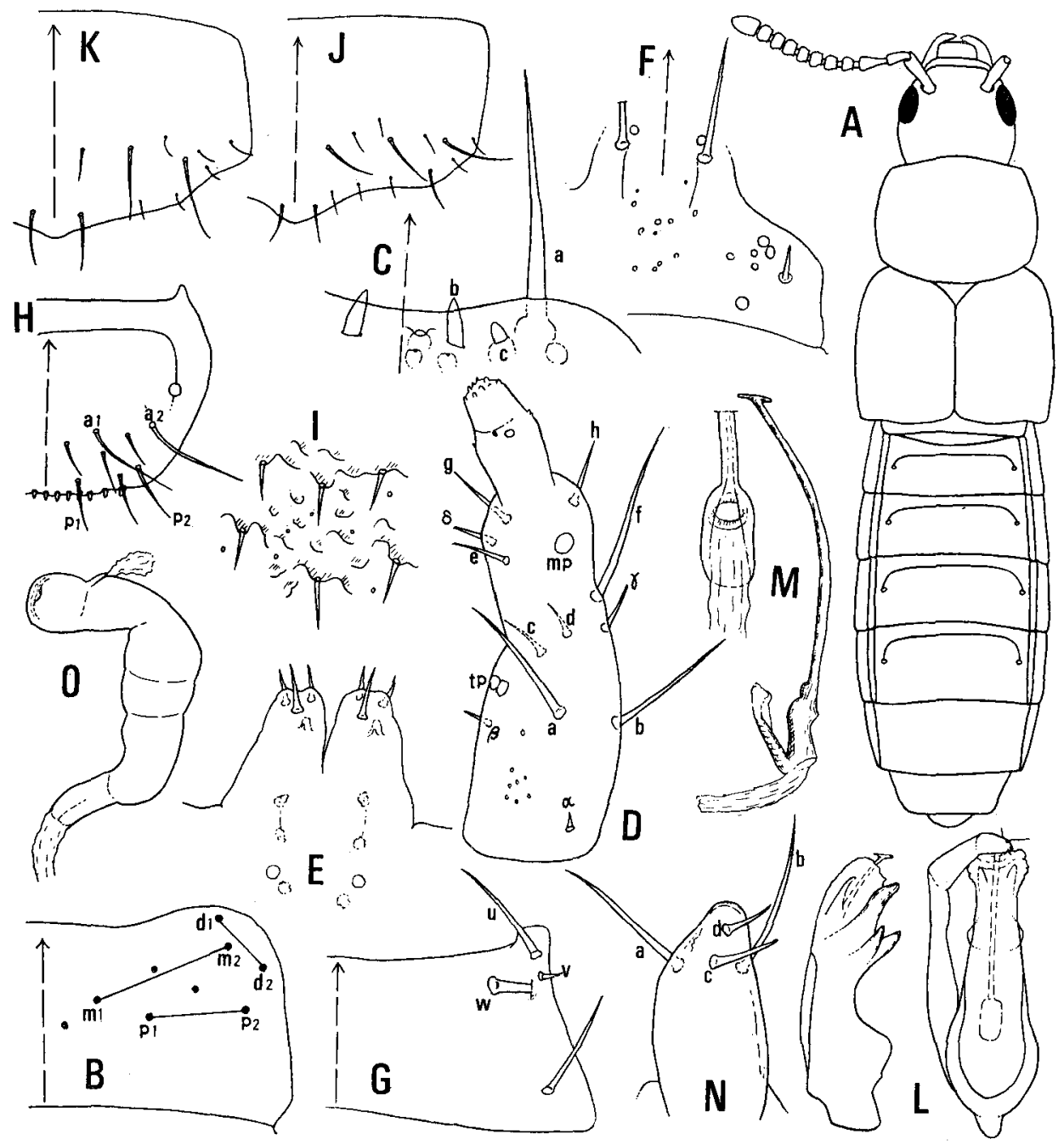

Fig. 8. Aleochara (Emplenota) fucicola Srarp, 1874 from Seto. A, Habitus; B, Labral chaetotaxy; C, Labral margin; D, Labial palpus; E, Glossa; F, Prementum; G, Mentum; H, Terg. VIII; I, Microsculpture of terg. VIII; J, Stern. VIII $\hat{o} ; \mathrm{K}$, do. $9 ; \mathrm{L}$, Aedeagus (dors. and lat. view); M, Copulatory piece (dors. and lat. view); N, Distal sclerite of paramere (left); O, Spermatheca.

and there is no isolated spines. Galea is gently arcuate on the outer margin; there are 2 sensory pores, one is placed at base together with a few micropores and theother is apical in position; the distal lobe is densely ciliate even in the basalmost portion and basal setaceous sensillae are poorly differentiated. Labial palpus is distinctly 
3-segmented; the distal segment is narrower than the preceding and crowned by a verrucose, obtuse apex; the setae are reduced as a whole; setula $\alpha$ is inwardly removed; $\beta$ is separating from $t p ; \gamma$ is placed behind $f ; \delta$ is much longer than $\beta$ and on the same level with $m p ; a$ is located between tp and $b$; the latter is on the level of $a$ and far remote from $f ; c, d$ are subequally short; $e$ is unusually short and placed close to $\delta$. Glossa is short and broad, dilated proximally; each arm is truncate apically and with 3 strong spines on apex. The median area of prementum is broad, with a few, reduced pseudopores; 3 real and 1 setal pores are present in the lateral area. Mentum is strongly transverse, distinctly emarginate and with numerous micropores; seta $u$ is at the base of the produced corner; $v$ is reduced; $w$ is more than three times as long as $u$. Pronotum is poorly convex above and not modified, but a faint median depression before the base is to be observed in some specimens; besides a long seta on the middle the erecting lateral setae are reduced; the surface is more finely punctured than on the head and densely sculptured throughout. Elytron is a little emarginate posteriorly, coarsely and densely punctured and sculptured. Metathoracic wing is present. Ratio of tarsal segments as: 11:12:11.5:24 in fore-; 15:14: 13:13:29 in mid-; 21:16:15:15:32 in hind-legs. Empodium is usually longer than the claw in all legs. Abdomen bears dense punctures, but sparser and finer toward the extremity. Tergite VIII is entirely truncate on the posterior margin, it is fringed with a row of short, blunt spinulae; the principal setae are ca. 8 in number, from which 3 shorter ones are variable in number and loci; the microsculpture of the middle is neither reticulate nor imbricate, it is warty or irregularly wavy as in fig. I. Sternite VIII is short, obliquely truncate and with more or less pointed apex; 5 long, 8 short and some other setae are present.

Aedeagus is $0.69 \mathrm{~mm}$ in length. In dorsal view the median lobe is narrowly elongate, with dilated apex. In lateral view the apical lobe is simply pointed on apex and with 2 stout processes at the base. Copulatory piece is $0.53 \mathrm{~mm}$ long; the apical process is very long, spiny and with a crutched apex; the corpus is small and oblong in dorsal view; the suspensorium is reduced and lying beneath the corpus. Distal sclerite of paramere is narrowly rounded on apex; seta $a, b$ are similarly long and arranged in a transverse row, while $b, c$ are smaller and longitudinal in position.

Length. $4.10 \mathrm{~mm}$ (Head long $0.56 \mathrm{~mm} \times$ wide $0.60 \mathrm{~mm}$; pronotum $0.66 \mathrm{~mm}$ $\times 0.68 \mathrm{~mm}$; elytra $0.84 \mathrm{~mm} \times 1.00 \mathrm{~mm}$ ).

ㅇ. Compared to males the sternite VIII is not sinuate and less distinctly produced apically; there are usually 3 long and 7 short principal setae. Spermatheca is peculiar by the uncoiled and almost straight duct with some constrictions; the bursa is short, with reduced umbilicus and small appendix near the apex.

Specimens examined: 4 ex. Shingu, 14. IV. 1970, Dr. R. Yosr leg., 4 ex. Seto, 7. V. 1969, K. Sawada leg., 1 ex. Hatakejima in Seto, 8. V. 1969, K. Sawada legs., 1 ex. Susami, 3. VII. 1970, K. Sawada leg., 1 ex. Mirozu, 3. VII. 1970, K. Sawada leg., 5 ex. Kirimezaki, 15. V. 1970, K. SAwada leg., 5 ex. Tomogashima off Kada, 
20. V. 1970, K. Sawada leg., all from Pref. Wakayama. 4 ex. Akashi, Pref. Hyogo, 22. V. 1969, K. SAwada leg., l ex. Yuigahama in Kamakura, Pref. Kanagawa, 30. V. 1970, Dr. R. Yosir leg., 3 ex. Wakasa-Takahama, Pref. Kyoto, 20. V. 1969, K. SAwada leg., 1 ex. Hagi, Pref. Yamaguchi, 29. VII. 1969, Dr. R. Yosi leg., 4 ex. Magarizaki, 5. V. 1970, Dr. R. Yosir leg., 5 ex. Tororo, 5. V. 1970, Dr. R. Yosi leg., all from Amakusa, Pref. Kumamoto.

This species is distinguished by the chaetotaxy of labial palpus and by the secondary sexual characters of the male. The reduced setae of labial palpus, the furcate aedeagus and uncoiled spermatheca are probably the characteristics of the subgenus Emplenota Casey. This species is near the European $A$. (E.) grisea KraAts, 1856 (sensu Ganglbauer, 1895), but differs by the longer and more finely punctured head, narrower pronotum and by the larger body size. Sharp has described the species from Amakusa, but the species is one of the commonest element of Aleocharinae to be found under wrack of the sea-shore everywhere along the coast of Japan.

\section{Aleochara (Triochara) trisulcata WEISE, 1877}

(Fig. 9)

o. Nearly black and subopaque. Elytra are tinged with brown; antennae, trophi and legs are evenly brown, but the former is slightly infuscate toward the extremity. Head is gently convex above, with a paired, longitudinal sulci on each side of the middle, they are connected by a transverse depression before the base; coarse, irregular punctures with some erecting setae are covering these depressions; similar coarse punctures are aggregated on the post-ocular region as far as the supreorbital part without forming sulcus; a supre-orbital carinula is present along the margin of the eye; the integument is finely punctured and with dense microsculpture. Eye is large, with minute cornea and short, sparse pubescence. Antenna is short; ratio of segments as: I $35 \times 14:$ II $20 \times 11.5:$ III $12 \times 11.5:$ IV $8 \times 11.5: \mathrm{X} 8 \times 16$ : $\mathrm{XI} 21 \times 16$. Labrum is broadly emarginate and with numerous micropores; setae are stout and gradually tapering distally; seta $p-1$ is near the middle of $m-1$ and $m-2$ and much longer than $p-2$ : all rows are subequally short and confined to the anterior part of the labrum; one long secondary seta is always present. Labral margin is alike to $A$. (E.) fucicola SHARP. 1874, but $a$-sensilla is close together and $b$ is smaller. Left mandible is infolded apically forming a thick apical hook and with a basal toothlet; the right one is pointed and with crenate inner margin; prostheca has a row of marginal cilia, the basal ones being serrate. Maxillary palpus is stout; segment I isl onger than broad; II is incrassate, lightly broader than III and with coarse marginal setae but without reticulation; III is a little longer than the preceding and with some coarse setae and micropores; IV has long filamentous sensillae at the base; V is clearly segmented and verrucose on apex. Instead of the distal comb of lacinia there are ca 10 long spines. Galea is short for the lacinia and with several, sensory pores; the 
distal lobe is acuminate to pointed apex and with long, thick cilia; the basal setaceous sensillae are not observed. Labial palpus is distinctly 4 -segmented: setula $\beta$ is unusually long, subequal to $\gamma$ in length; the latter is placed at about the middle

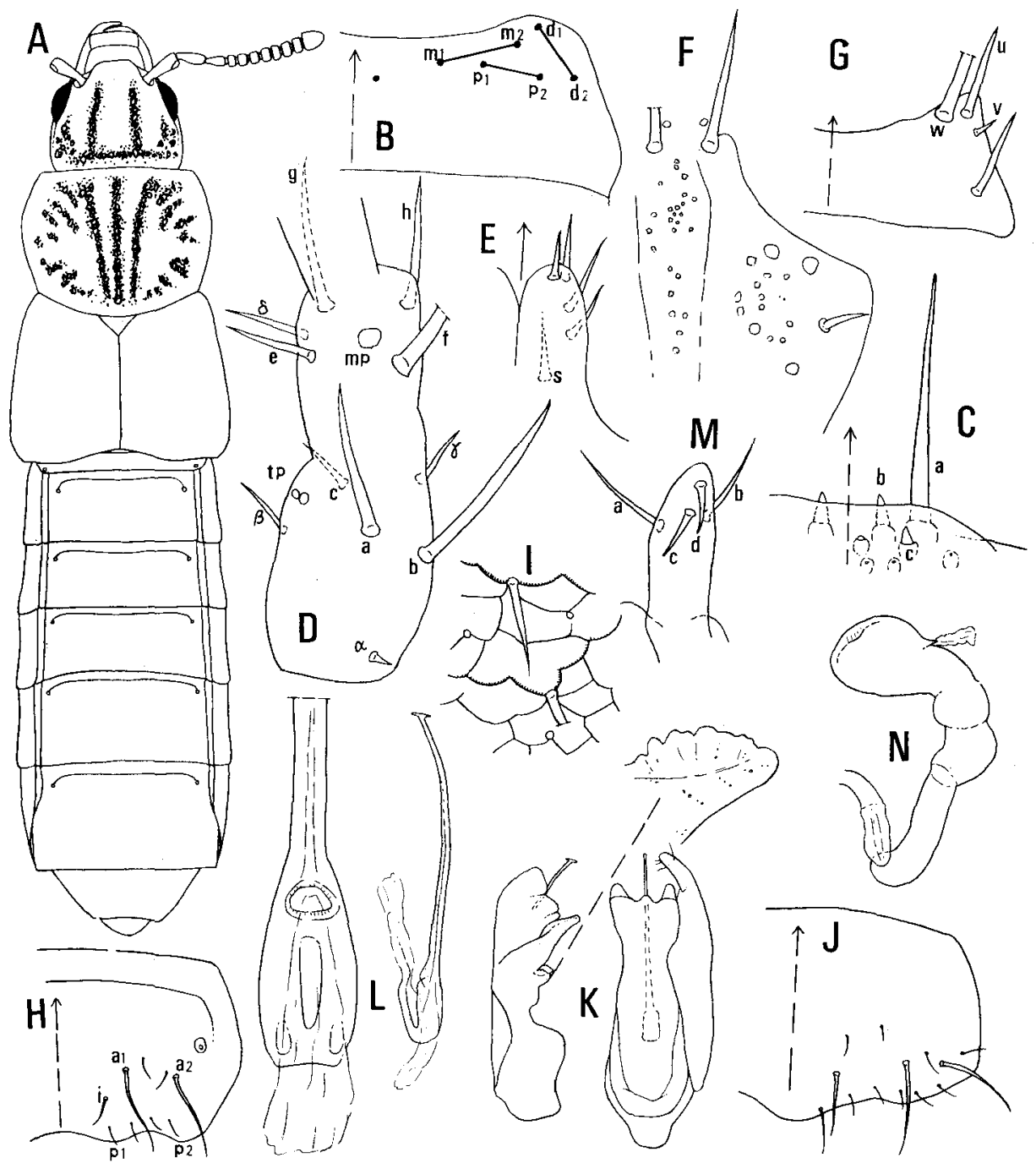

Fig. 9. Aleochara (Triochara) trisulcata WeIse, 1877 from Seto. A, Habitus; B, Labral chaetotaxy; C, Labral margin; D, Labial palpus (right); E, Glossa; F, Prementum; G, Mentum; H, Terg. VIII; I, Microsculpture of terg. VIII; J, Stern. VIII; K, Aedeagus (dors. and lat. view); L, Copulatory piece (dors. and lat. view); M, Distal sclerite of paramere (left); N, Spermatheca.

between $b$ and $f$, which are wide apart to each other; $\delta$ is also well-developed and long; seta $d$ is usually absent; $e$ is subequal to $\delta$ in length and close to it. Glossa is forked into 2 rounded arms each provided with 5 spines, but the basal one (s in 
fig. E) is often missing. The median area of prementum has many scattered, fine pseudopores; in the lateral area the setal pore is laterally situated together with poor real pores and a few pseudopores. Mentum is deeply emarginate; seta $w$ is placed close to $u ; v$ is variable in length, rarely duplicated. Pronotum is gently convex above, with 3 deep longitudinal sulci, somewhat converging posteriorly, they are adorned with the same coarse punctures as in the head. Similar punctures are present on the lateral area in irregular structure; there are 2 strong setae on the lateral margin. Elytron is lightly emarginate posteriorly; punctures and microsculpture are as in the pronotum, but smaller and denser. Metathoracic wing is present. Ratio of tarsal segments as: 13:10:10:10:19 in fore-; 18:14:13:13:12 in mid-; 24:17:16:15:27 in hind-legs. The segment I to III of the fore tarsus have some obtuse denticles. Empodium is subequal to the claw in length. Abdomen is finely and roughly punctured basally becoming coarser toward the extremity. Tergite VIII is bisinuate on the posterior margin; the principal setae are $9+9(4$, $1,4)$ in number; $a-1, a-2$ are long, while others are fine setulae arranged as in fig. $\mathrm{H}$; the intermediate seta ( $\mathrm{i}$ in fig. $\mathrm{H}$ ) is a little larger than the posterior setulae.

Aedeagus is $0.68 \mathrm{~mm}$. In dorsal view the median lobe is narrowly elongate and fairly constricted anteriorly; the membraneous apical margin is slightly produced at the middle. In lateral view the apical lobe is more or less protruded beyond the median lobe and with 2 processes at the base as in the preceding species, but when precisely observed each process is smaller and irregularly serrate along its anterior margin. Copulatory piece is styliform and clutched apically; the corpus is effaced anteriorly and with a large, elongate fenestra behind the annellus. Distal sclerite of paramere is narrowly rounded apically; seta $c, d$ are slightly shorter than $b$.

Length. $4.20 \mathrm{~mm}$ (Head long $0.63 \mathrm{~mm} \times$ wide $0.74 \mathrm{~mm}$; pronotum $0.78 \mathrm{~mm} \times$ $0.94 \mathrm{~mm}$; clytra $0.88 \mathrm{~mm} \times 1.10 \mathrm{~mm}$ ).

ㅇ. The sternite VIII is not sinuately produced in the middle, but merely narrowed to an obtuse apex. Spermatheca is $0.26 \mathrm{~mm}$; the duct has 2 dilations and long anterior part; bursa is robust, with a very obsolete umbilicus.

Specimens examined: 5 ex. Seto, 7. V. 1969, K. SAwada leg., 1 ex. Hatakejima in Seto, 8. V. 1969, K. SAwada leg., l ex. Tomogashima off Kada, 28. V. 1970, K. SAwada leg., all from Pref. Wakayama. 1 ex. Yuigahama in Kamakura, Pref. Kanagawa, 30. V. 1970, Dr. R. Yosi leg.

Notwithstanding its stong exterior characters the shape of mouth-parts and the characters of the male and the female indicate that the species is a near relative of the subgenus Emplenota CASEY. This species is unique in the modification of head and pronotum as well as in the characters of the male.

\section{Résumé}

From the campus of the Seto Marine Biological Laboratory nine species of Aleocharinae have been collected including four species new to science. Of these 
nine, two species are from the floor of the forest of Pinus thunbergii, while the rest seven are found among the heap of the wrack of Sargassum along the sea-shore. There is no species common to these two habitats. This fact implies that the Aleocharinae species of the wrack are mostly halophilous and exclusively adapted to the life on the sea-shore.

\section{REFERENCES}

Adachi, T., 1957. The Staphylinid Fauna of Japan. Jour. Toyo Univ., 11: 1-35.

Bernhauer, M., 1907. Die Staphylinidenfauna von Japan. Verh. zool-bot. Ges. Wien, 57: 371-414. Bernhauer, M. et Scheerpeltz, O., 1926, 1934. Coleopterorum Cat., 82: 500-798, 130: 1524-1723.

Blackwelder, R.E., 1952. The Generic Names of the Beetles Fam. Staphylinidae. U.S. Nat. Mus. Bull, 200: 483 pp.

Cameron, M., 1933. New species of Staphylinidae from Japan. Ent. month. Mag., 1933: 160-175, 208-219.

Fenyes, A., 1918-1921. Genera Insectorum. subfam. Aleocharinae: $453 \mathrm{pp}$.

Ganglbauer, L., 1895. Die Käfer von Mitteleuropa, II : $880 \mathrm{pp}$.

Hansen, V., 1954. Rovbiller 3. Del. Danm. Fauna, 59: 499 pp.

Sawada, K., 1955. Marine Insects of the Tokara Islands VII. Fam. Staphylinidae. Publ. Seto Mar. Biol. Lab., 5 (1): 81-87.

1970. Aleocharinae of the IBP-Station in the Shiga Heights I, Bull. Sci. Mus. Tokyo, 13 (1):

21-64. ditto II, Contr. Biol. Lab. Kyoto Univ., 23 (1): 33-60.

Scheerpeltz, O., 1929. Staphyliniden aus Palästina und Syrien. Sitzungsb. math.-naturw. k1, Abt. I 138. 250-356.

Sharp, D., 1874. The Staphylinidae of Japan. Trans. Ent. Soc. London, 1874 (1): 1-103.

—_ 1888. The Staphylinidae of Japan. Ann. Mag. Nat. Hist., $6: 277-377$.

Weise, J., 1877. Japanische Staphylinidae und Pselaphidae. Deut. Ent. Zeit., 21: 88-97.

Postscript: After the manuscript was sent I have dissected the type specimen of Ischnopoda (Stethusa) miyamotoi K. SAwADA 1955, described from the sea-shore of the Tokara Islands. To my great regret it is concordant point for point with Myrmecopora (s. str.) algarum (Sharp. 1874), so that it falls in the junior synonym of the latter species. 